\title{
Pasajes del Macer Floridus castellano en el ms. II-3063 de la Real Biblioteca
}

\author{
Interpolation of text from the Castilian Macer Floridus \\ in ms. II-3063 of the Real Biblioteca
}

Jesús Pensado Figueiras

Universidad de A Coruña

RESUMEN: El análisis textual del códice II-3063 de la Real Biblioteca (Palacio Real de Madrid) ha permitido localizar una nueva versión de varios pasajes de la obra de fitoterapia latina De viribus herbarum, más conocida por Macer Floridus. El texto del manuscrito II-3063 recoge, de manera interpolada, las virtudes de seis plantas descritas en el texto latino y confirma la hipótesis de una sola traducción del latín a una lengua romance peninsular, de la que saldrían nuevas versiones posteriores hasta obtener la nómina actual de textos del Macer Floridus en catalán, aragonés y castellano.

Palabras clave: Fitoterapia, Macer Floridus, traducción científica medieval.

ABSTRACT: Textual analysis of codex II-3063 of the Real Biblioteca (Royal Palace, Madrid) has located a new Castilian version of several passages from the Latin work on herbalism De viribus herbarum, better known as Macer Floridus. The text of codex II-3063 contains interpolated descriptions of the virtues of six plants outlined in the Latin text and confirms the hypothesis of a single translation from Latin into a peninsular Romance language, from which later versions would be made until the current number of texts of the Macer Floridus in Catalan, Aragonese, and Castilian was reached.

Keywords: Phytotherapy, Macer Floridus, Medieval scientific translation. 


\section{INTRODUCCIÓN*}

La difusión del herbario Macer Floridus en las lenguas romances de la Península Ibérica plantea interrogantes que han despertado el interés de diversos especialistas desde la última década del siglo XX. Thomas M. Capuano ${ }^{1}$ ha sido el primero en abordar la cuestión de la primera traducción del latín al romance y de las posteriores versiones a los distintos idiomas del actual territorio español. Guido Mensching ${ }^{2}$ vuelve sobre esta cuestión, pero ya con otros textos en su haber que le ofrecen una visión más amplia del recorrido realizado por la obra De viribus herbarum, de este lado de los Pirineos. Este herbario, más conocido por el nombre de Macer Floridus ${ }^{3}$, atribuido a un llamado Odo Magdunensis ${ }^{4}$, es una de las obras médico-botánicas más populares de la Edad Media. Su fama se extendió con rapidez y conoció traducciones tempranas en el área occitana de Francia y en la Península Ibérica. Su difusión se mantuvo hasta que los intelectuales renacentistas comenzaron a traducir, editar y comentar las fuentes médicas grecolatinas, en particular los Opera omnia de Dioscórides, su fuente más recurrida ${ }^{5}$, que condujeron al Macer Floridus a un olvido progresivo a partir del siglo $\mathrm{XVI}^{6}$. T. Capuano realiza el inventario de las lenguas a las que se tradujo este herbario: «Catalan, German, French, Danish,

\footnotetext{
* Agradezco a Arsenio Ferraces Rodríguez su magisterio y sus inapreciables observaciones para dar forma definitiva a este artículo.

1 Thomas M. Capuano, «Medieval iberian vernacular versions of the herbal called Macer Floridus», Manuscripta, a journal for Manuscript Research, Saint Louis-Missouri, November, 1991, págs. 182-202.

${ }^{2}$ Guido Mensching, «El Macer Floridus en la Península Ibérica: efectos y efectos secundarios de un herbario medieval», en $\mathrm{M}^{\mathrm{a}}$. T. Navarro, J. J. Nitti y $\mathrm{M}^{\mathrm{a}}$. N. Sánchez, coords., Textos medievales y renacentistas de la Romania, New York, Madison, Hispanic Seminary of Medieval Studies, University of Wisconsin, 2002, págs. 93-109. El mismo autor también estudia la traducción hebrea de esta misma obra: Bos Gerrit y Mensching Guido, «Macer Floridus: A Middle Hebrew Fragment with Romance Elements», The Jewish Quarterly Review, New Series, 91, 1/2 (Jul. - Oct.), 2000, págs. 17-51.

${ }^{3}$ Macer Floridus, De viribus herbarum, ed. y notas de L. Choulant, Leipzig, Leopold Vossii, 1832.

4 Johannes Gottfried Mayer y Konrad Goehl, Kräuterbuch der Klostermedizin: Der «Macer Floridus», Medizin des Mittelalters, Holzminden, Reprint-Verlag-Leipzig, 2003.

5 Para más detalles sobre la difusión de Dioscórides en la alta Edad Media, cfr. Arsenio Ferraces Rodríguez, Estudios sobre textos latinos de fitoterapia entre la Antigüedad tardía y la Alta Edad Media, A Coruña, Universidade da Coruña, 1999.

${ }^{6}$ Baste decir que el libro de Jerónimo Soriano, Libro de experimentos medicos, faciles y verdaderos, recopilados de grauissimos autores (Zaragoza, 1598), transmite una receta de la «Satureia» del De viribus herbarum, indicando «De vn heruario antiguo» (ed. de $\mathrm{M}^{\mathrm{a}}$ Teresa Herrera y $\mathbf{M}^{\mathrm{a}}$ Estela González de Fauve, Madison, Hispanic Seminary of Medieval Studies, University of Wisconsin, 1997, f. 20r).
} 
Italian, Middle Dutch and Middle English», nombrando más adelante el castellano. Habría que añadir el occitano a esta lista, cuyo texto fue editado por Clovis Brunel ${ }^{7}$ y completado más tarde por Maria Sofia Corradini Bozzi ${ }^{8}$. También es importante citar la traducción al aragonés, de la que da noticia Guido Mensching.

El sudoeste de Europa asistió así a la mayor difusión en romance del texto latino, con un buen inventario de códices, al que se añaden dos nuevos textos. El primero se localiza en el Códice Zabálburu de Medicina Medieval, ff. 39rb$61 \mathrm{vb}$, transcrito por Carmen Sánchez Téllez ${ }^{9}$. El segundo, fragmentario y bastante breve, en el ms. BNM 2328 ff. $68 \mathrm{r}-81 \mathrm{r}^{10}$. La relación de manuscritos conocidos hasta la actualidad en el sur de Francia y la Península Ibérica es, pues, la siguiente:

- Occitano

\begin{tabular}{|c|c|c|}
\hline & $(P)$ & Princeton, Garrett 80. \\
\hline & (A) & Auch, Ardchiv. Dép. du Gers I 4066. \\
\hline & $(\mathrm{Ca})$ & Chantilly, Musée Condé 330, versión en verso. \\
\hline & $(C b)$ & Chantilly, Musée Condé 330 , versión en prosa ${ }^{11}$. \\
\hline - Castellano & & \\
\hline & $(Z)$ & $\begin{array}{l}\text { Códice Zabálburu de medicina medieval, transcripción de Car- } \\
\text { men Sánchez Téllez. }\end{array}$ \\
\hline & $(M A C)$ & $\begin{array}{l}\text { Macer herbolario. Sevilla, Bibl. Colombina 7-6-27-1, edición } \\
\text { de Porter Conerly, Ardemagni y Richards }{ }^{12} \text {. }\end{array}$ \\
\hline & $(K)$ & $\begin{array}{l}\text { ms. } 3369 \text { de la Biblioteca Nacional de Madrid, (f. 169v-170), } \\
\text { transcrito por Richard P. Kinkade }{ }^{13} \text {. }\end{array}$ \\
\hline & $(E)$ & ms. BNM 2328 ff. 68r-81r. \\
\hline
\end{tabular}

${ }^{7}$ Clovis Brunel, Recettes médicales, alchimiques et astrologiques du XV siècle en langue vulgaire des Pyrenées, Toulouse, Édouard Privat, 1956.

8 María Sofía Corradini Bozzi, Ricettari medico-farmaceutici medievali nella Francia meridionale, vol. I, Firenze, Olschki Ed., 1997.

${ }^{9}$ Anónimo, Códice Zabálburu de Medicina Medieval, trscr. de C. Sánchez Téllez, Alcalá de Henares, Universidad de Alcalá, 1997. Aunque utilizo esta transcripción como base para el estudio, la edición de los textos de Zabálburu que figuran en este artículo es propia, resultado de la confrontación del trabajo de Sánchez Téllez con el manuscrito Antiguo Medico de la bibliotecaarchivo Francisco de Zabálburu (Madrid).

${ }^{10}$ Para la descripción y transcripción de estas dos versiones, cfr. mi tesis doctoral: Jesús Pensado Figueiras, El códice Zabálburu de medicina medieval: Edición crítica y estudio de fuentes, Tesis doctoral, Universidade da Coruña, La Coruña.

${ }^{11}$ María Sofía Corradini Bozzi, Ricettari..., cit. Seguiré la nomenclatura establecida por esta autora.

12 (MAC) Macer herbolario. Sevilla, Bibl. Colombina 7-6-27-1, Ed. Porter Conerly, Enrica J. Ardemagni y Ruth C. Richards, Madison, Hispanic Seminary of Medieval Studies, University of Wisconsin, 1986.

${ }^{13}$ Richard P. Kinkade, «Un nuevo manuscrito de la Semeiança del mundo», Hispanic Review, 39, 1971, págs. 261-262, transcrito en la nota 2 de este artículo. Sólo recoge la descripción completa del «apio»y algunas virtudes del «ala». 
- Catalán

(F) Lluís Faraudo de Saint Germain, «Una versió catalana del libre de les herbes de Macer, en Estudis Romanics, v. 5, Barcelona, Institut d'estudis catalans, 1955-1956 ${ }^{14}$.

(V) Macer, Llibre de les herbes i les seues virtuts, I, Transcripcio, edicio i introduccio d'Alicia Palazón, ed. L'Oronella, serie L'Alfardó, $n^{\circ}$ 2, Generalitat valenciana, Conselleria d'agricultura, peixca i alimentació, Valencia, $2001^{15}$.

(S) Tractat de les herbolaris del mestre Macer, Bibl. Colombina, Sevilla, con signatura ms. 7-4-27, ff. 20rb-31va.

— Aragonés

(G) Pasajes citados en el artículo de Mensching, 2002.

\section{INTERPOLACIÓN DEL MACER FLORIDUS EN EL MANUSCRITO RB II-3063}

El objeto del presente artículo es incluir en el inventario de textos romances peninsulares del De viribus herbarum una interpolación de unos pasajes de este herbario identificada en un recetario castellano fechado en 1471:

- Castellano

$(S D M)$ Real Biblioteca (RB) II-3063, ff. 13va-14va ${ }^{16}$.

${ }^{14}$ Usaré la edición de Faraudo de Saint-Germain para presentar los pasajes en catalán. Para completar la transmisión catalana de este herbario es imprescindible consultar el artículo de Laura Ramello, que descubre y analiza una interpolación de dos pasajes del Macer Floridus, a partir de una traducción independiente, incluida en un recetario catalán: Laura Ramello, «Una raccolta di ricette in antica lingua catalana (codice palatino 1052 della Biblioteca Nazionale di Firenze)», Quaderni di Filologia Romanza, II, 1994, págs. 99-136.

15 Esta edición sustituye a la ya clásica de Barberá en la Revista Valenciana de Ciencias Médicas, tomos del 7 al 10 (1905-1908). Existe una reescritura de este texto en valenciano actual, con la siguiente referencia: Macer: Llibre de les herbes i les seues virtuts, II, actualisacio, ed. e intr. F. Tarazona, Valencia, L’Oronella, serie L'Alfardó, no 3, Conselleria d'agricultura, peixca i alimentación de la Generalitat valenciana, 2002.

${ }^{16}$ La interpolación se localiza en un texto conocido como Secretos de la medicina y se acepta su atribución a Juan Enriquez. Hay dos transcripciones de este texto: Marie Lenkiewicz, Contribución al estudio del léxico médico del español medieval: «Secretos de medicina» del licenciado don Juan Enríquez y «Pronóstica del pseudo-Galeno», tesis de «Master of Arts», Department of Hispanic Studies Mc Gill University, Montreal, 1987; Juan Enríquez, Secretos de la medicina, Madrid, Biblioteca de Palacio 3063, ed. E. Jiménez Ríos, Madison, Hispanic Seminary of Medieval Studies, University of Wisconsin. Mantengo la abreviatura SDM otorgada por Jiménez Ríos, aunque no así su foliación. En este aspecto sigo la numeración del catálogo de la Biblioteca de Palacio (http://realbiblioteca.patrimonionacional.es). En la lista de obras transcritas por el equipo Madison se cita a Enrique Jiménez Ríos y de él es el folleto-prólogo de este texto. Sin embargo, el que figura en la base de datos del Corpus Diacrónico del Español (CORDE) [RAE, http://www.rae.es] indica que el editor es Andrea L. Arismendi, también para el Seminario de Madison, en 1995. Por su parte, la base de datos http://www.corpusdelespanol.org atribuye la edición a John ONeill, también para Madison, pero en 1999. La transcripción es la misma en los 
El texto en el que se incluyen los pasajes del Macer Floridus expone en su mayor parte (ff. $2 \mathrm{r}^{17}$-13va) recetas provenientes del Thesaurus Pauperum ${ }^{18}$, ordenadas por dolencias y respetando por regla general la estructura del recetario de Pedro Hispano. No son traducción de esta obra los folios situados al comienzo del texto ${ }^{19}$, que relacionan las partes del cuerpo con los humores, cuya fuente aún desconozco; tras el fragmento del Macer Floridus continúa el recetario ${ }^{20}$, también ordenado por dolencias pero sin seguir el orden clásico $a$ capite ad calcem; parte de estas recetas son, asimismo, traducción parcial del capítulo De pleuresi del Thesaurus Pauperum. El inicio de los pasajes que traducen el De viribus herbarum es abrupto ${ }^{21}$, sin incipit y deja truncada una receta anterior. Presento seguidamente la transcripción de este pequeño herbario:

\section{TRANSCRIPCIÓN ${ }^{22}$}

$113 \mathrm{va} /$ Capitulo para el dolor del vientre.

E dize Galieno que el estiercol del lobo que sea buelto con azeyte \& sea puesto sobre el dolor luego sanara. Mas dize que sy lo pudiere auer rezjente que non conujene que otra cosa njnguna le bueluan, que de sy mesma sana esta enfermedad. ${ }^{23}$

Capitulo. para el dolor del vientre.

E dize galieno que para esta enfermedad sanar... ${ }^{24}$

tres casos. Enrique Jiménez Ríos menciona a Macer en el prólogo a su transcripción, pero como uno más de los autores mencionados en SDM. En ningún momento alude a esta tradición directa del Macer Floridus en la que, además, no figura el nombre de ninguna autoridad. La tesis de M. Lenkiewicz dice lo siguiente con respecto al fragmento que nos ocupa (pág. xxx): «Empieza a continuación una nueva parte que versa sobre las virtudes y aplicaciones médicas de seis plantas: el beleño, el culantro, el espliego, la peonía, el ala y el pelitre».

${ }^{17}$ El folio $1 \mathrm{v}$ recoge también recetas que permanecen inéditas.

${ }^{18}$ Lenkiewicz ya había identificado parte de la traducción del Thesaurus Pauperum en este texto: Lenkiewicz, Contribución..., cit., págs. xxxi, lxx y lxxi. He confrontado la traducción castellana con la edición latina de María Helena Da Rocha Pereira, Obras médicas de Pedro Hispano, Coimbra, Acta Universitatis Conimbrigensis, 1972.

19 ff. $2 \mathrm{r}-5 \mathrm{ra}$.

${ }^{20}$ ff. 14 va-15rb.

${ }^{21}$ f. $13 \mathrm{va}$, línea 11.

${ }^{22}$ Ofrezco el texto realizado a partir del cotejo con las transcripciones de Lenkiewicz y Jiménez Ríos y con el análisis del propio manuscrito. He independizado cada virtud en línea distinta (en el manuscrito están separadas por calderones o no presentan ninguna marca física). $\mathrm{He}$ resaltado en negrita el inicio de la descripción de cada planta. También he incluido los pasajes anterior y posterior a esta interpolación, a fin de ofrecer una idea cabal de su situación en el conjunto del texto.

${ }^{23}$ Thesaurus Pauperum, XXII, 18.

${ }^{24}$ El Thesaurus Pauperum atribuye a Galeno la receta XXII, 19: «Item marrubium album coctum in oleo oliuarum, tritum et appositum, mirabiliter sedat dolorem. Galenus». No obstante, 


\section{$<$ Comienzo del Macer Floridus $>$}

Virtudes del veleño ${ }^{25}$. Toma las fojas \& majalas \& ayuntalas con la farina del ordio o çeuada, que todo es vno; \& fazlo enplasto \& ponlo sobre las finchaduras \& sanara.

E toma el çumo \& metelo en las orejas que tienen dolor \& sanaran.

Otrosy, toma la semjente \& la rayz desta dicha yerua \& cuezelo con vinagre \& metelo en la boca fasta que faga espuma \& sanara el diente que duele.

Otrosy, toma el çumo desta yerua \& echalo en los ojos \& sanaran.

Otrosy, toma el çumo desta dicha yerua \& echalo dentro en la natura de la muger \& estañarle ha la sangre luuja.

Otrosy, toma el çumo desta yerua \& ayuntalo con farina de ordio \& faz enplas $/ 13 \mathrm{v} /$ to \& ponlo sobre los conpañones del omne que estoujeren jnchados o sobre las tetas de las mugeres \& sanaran.

E faz venjr las carnes nueuas.

Virtudes del culantro. Es frio \& vmjdo. E dize Galieno que si el çumo del es beujdo con vjno o con vjnagre mata las lonbrjzes.

Otrosy, sy lo mesclas con vinagre \& con mjel \& sea bien pisada \& beujda quita todo dolor de todos los mjenbros.

E esta confaçion es mucho prouechosa para la finchazon de los conpañones.

Otrosy, la semjente desta yerua molida \& beujda muchas vezes con agua estaña la corrençia.

Otrosy, toma la espuma del argen \& la escoria \& el çumo del culantro \& el vjnagre \& ayuntalo todo \& faz vnguento muy prouechoso para el fuego saluage \& para las finchaduras.

Otra virtud, que sy el çumo desta yerua es mezclado con farina de ordio $\&$ puesto sobre las postillas, sanalas, \& las señales \& enpeynes que nasçen en el pescueço.

Otrosy, el que ha terçiana coma tres granos del culantro ante que le venga la terçiana \& sanara. flor.

Otrosy, coma tres granos $/ 14 \mathrm{ra} /$ desta yerua la muger \& estañarle ha su

Virtudes del espriego. Si es beujdo con vjno conforta todo el estomago.

E cuezelo con vjno \& beuelo \& purgara las renes \& la vexiga \& faz bien mear \& estaña la sangre de la muger \& quita el dolor de las piernas.

E sy es metida en la natura de la muger estanca la sangre luuja.

E cueze esta yerua con vjno \& laua los ojos que comen con el \& sanaran.

Para la gota que derriba. Toma la peonja \& atala al cuello del enfermo.

no es posible concluir que el comienzo de la receta castellana haga referencia a ésta latina, pues el recetario de $S D M$ no sigue fielmente el orden establecido por el Thesaurus Pauperum y en este capítulo hay diez recetas atribuidas a Galeno después de la 19. La atribución de estas recetas tampoco es fiable; por ejemplo, la anterior ( $T P$, XXII, 18), atribuida aquí a Galeno, se atribuye a Gilbertus en el Thesaurus Pauperum.

25 Jiménez Ríos: beleño 
E si esta yerua es beujda, purga la piedra de la vexiga \& faz bien mear.

Otrosy, la peonja pisada con almendras \& beujda con agua o con vjno, aprouecha mucho al espien \& al vientre \& renes \& purga sobejanja de la sangre de la muger.

Yten, sy esta yerua es cocha con vjno \& beues della, aprouecha al dolor de la vexiga \& de las renes.

E si es beujda muchas vezes con agua o con vjno espanta la fantasma, la que suele pesar, que dizen la manpesadilla.

Otrossi, /14rb/ sy la rayz della es ligada al cuello aljuja a los que caen de gota. E esto es cosa prouada \& çierta.

Virtudes del ala. Si la cozieres con agua fazerte ha estancar la sangre mucha a la muger.

Otra virtud, que faze bien mear \& faze a la muger echar la criatura muerta del vientre \& faze bien salir a camara.

Otra virtud, sy es majada la rayz con vnto $\&$ puesto sobre la pierna que ${ }^{26}$ duele quita el dolor.

Virtudes para el dolor delos dientes. Toma el pelitre \& maxcalo bien con los dientes \& despues laua la boca con vjnagre fasta que faga espuma $\&$ sanaras. E esto mesmo faras para la finchadura de la gulilla \& de la [r]ubilla ${ }^{27} \&$ de la hinchadura de la lengua.

Otrosi, si vsas mucho el pelitre con la mjel ${ }^{28}$ aprouecha mucho a la gota que derriba si la lleua al cuello ligada \& olerla por las narizes.

Otrosy, qual quier omne que aya fiebre cuega el pelitre con oleo \& vntese con el \& sanara.

E vntese con ese [con ese] oleo el que ha perlesia \& sanara.

E eso mesmo el que non puede sudar vntese con $/ 14 \mathrm{va} /$ este oleo \& sudara.

Otrosy, sy vntas con este oleo todo el cuerpo no ayas mjedo de njngund frio.

E estas mesmas virtudes ha el gengibre que ha el pelitre.

\section{$<$ Fin del Macer Floridus $>$}

Para el dolor de los ojos \& de la axaqueca \& otras cosas. Toma vn çelemjn de farina de trigo cernjda quatro vezes...

\section{ANÁLISIS DE LA INTERPOLACIÓN}

Al no figurar estos pasajes a comienzo de folio, parece probable que el manuscrito del que surgió $S D M$ ya presentara una interpolación idéntica, que pasó desapercibida en la difusión posterior. No se sostiene, pues, la hipótesis de que la obra atribuida a Juan Enríquez se encuentre al inicio de la transmisión

\footnotetext{
${ }^{26}$ Jiménez, Ríos: quel

27 Jiménez Ríos: rubilla

28 Jiménez Ríos: myel
} 
de este nuevo testimonio del Macer Floridus. El primer capítulo no está marcado en el manuscrito por ningún tipo de rúbrica, aspecto que justifica que no se haya detectado con anterioridad. No obstante, no cabe duda de que se trata de un título de capítulo que independiza las virtudes de la planta indicada. Es más, este título coincide con el manuscrito $M A C$, el único castellano que recogía hasta ahora las virtudes del IUSQUIAMUS ${ }^{29}$ :

\begin{tabular}{|c|c|c|}
\hline Macer Floridus ${ }^{30}$ & $M A C$ & $S D M$ \\
\hline $\begin{array}{l}\text { (vv. 1940-1941) } \\
\text { Iusquiami foliis contritis } \\
\text { adde polentam, / Haec } \\
\text { adhibendo potes quosvis } \\
\text { curare tumores. }\end{array}$ & $\begin{array}{l}\text { [21v] capitulo lxxij. de las } \\
\text { virtudes de veleño Ueleño es } \\
\text { de fria natura Et es la } \\
\text { primera virtud del atal que } \\
\text { sy la pisas las fojas \& las } \\
\text { Ayuntas con faryna de ordio } \\
\& \text { las fazes enplasto \& las } \\
\text { pones sobre la finchadura } \\
\text { desfazela. }\end{array}$ & $\begin{array}{l}\text { [13va] Virtudes del veleño. } \\
\text { Toma las fojas \& majalas \& } \\
\text { ayuntalas con la farina del } \\
\text { ordio o çeuada, que todo es } \\
\text { vno; \& fazlo enplasto \& } \\
\text { ponlo sobre las finchaduras } \\
\& \text { sanara. }\end{array}$ \\
\hline
\end{tabular}

A partir de aquí se suceden de forma ininterrumpida la descripción de las virtudes de seis plantas, hasta el folio 14va, donde se expone la última virtud del PyreThruM. A continuación, tras una línea en blanco, aparece una nueva receta que no encuentra correspondencia en el herbario latino. Por lo tanto, este último capítulo no está truncado y termina en el mismo punto que en los textos catalanes del Macer Floridus.

La relación de plantas incluidas en la interpolación es la siguiente ${ }^{31}$ : veleño (IUSQUIAMUS, 61), culantro (CORIANDRUM, 29), espriego (SPICA, 75), peonja (PAEONIA, 49), ala (ENUlA, 44) y pelitre (PyRETHRUM, 67). De manera que $S D M$ presenta, en un orden diferente al del texto latino y de las otras versiones romances, las virtudes de seis plantas cuya fuente es el Macer Floridus latino. La disposición de las plantas es específica de este manuscrito y no responde a ninguna lógica aparente. Aun así, es posible afirmar que se trata de una nueva variante de la traducción castellana conocida, si bien presenta un estilo más formulario y libre de las anécdotas existentes en el texto original.

A pesar de su brevedad, la importancia de esta interpolación es de primer orden, por varios motivos. En primer lugar, confirma que los distintos textos peninsulares del Macer Floridus provienen de una misma traducción del texto latino, tal como sugiere Mensching al comentar el cotejo de un pasaje concre-

${ }^{29}$ Indico en latín el nombre de las plantas, según la nomenclatura de la edición de Ludwig Choulant, para evitar la alternancia de nombres castellanos y catalanes, que se usarán solamente como referencia a sus textos.

30 Sigo la edición de Ludwig Choulant, ya citada.

31 Indico entre paréntesis el nombre latino y el orden que corresponde a cada planta en la edición de Choulant. 
to $^{32}$. La cercanía del texto de $S D M$ con las demás versiones castellanas y catalanas ratifica plenamente esta hipótesis, que ya Capuano había planteado y que nadie pone en duda hoy en día. La importancia de estos fragmentos estriba en que constituyen una prueba de que ya existía en castellano la descripción de las virtudes de plantas como la SPICA o el PYRETHRUM, de las que hasta ahora sólo se conocían versiones en catalán. En consecuencia, el texto SDM abre nuevas vías para comprender cómo pudo ser el arquetipo del texto castellano del Macer Floridus.

Un simple cotejo de los textos basta para comprobar la semejanza de la versión de $S D M$ con las demás versiones castellanas y con las catalanas:

\begin{tabular}{|c|c|c|c|c|c|}
\hline $\begin{array}{l}\text { Macer } \\
\text { latino }\end{array}$ & $Z$ & MAC & $S D M$ & $K$ & $E$ \\
\hline $\begin{array}{l}\text { (vv. 1943- } \\
\text { 1944) } \\
\text { Auribus } \\
\text { infusus } \\
\text { vermes } \\
\text { succus necat } \\
\text { eius, / } \\
\text { Illarumque } \\
\text { solet varios } \\
\text { lenire } \\
\text { dolores. }\end{array}$ & & $\begin{array}{l}\text { [21v] Et sy } \\
\text { tomas el } \\
\text { çumo della \& } \\
\text { la pones en } \\
\text { las orejas } \\
\text { mata el } \\
\text { dolor. }\end{array}$ & $\begin{array}{l}\text { [13va] E } \\
\text { toma el } \\
\text { çumo \& } \\
\text { metelo en } \\
\text { las orejas } \\
\text { que tienen } \\
\text { dolor \& } \\
\text { sanaran. }\end{array}$ & & \\
\hline $\begin{array}{l}\text { (vv. 959- } \\
961) \\
\text { Hanc } \\
\text { Galienus } \\
\text { ait, per } \\
\text { quam } \\
\text { depellere } \\
\text { ventre / } \\
\text { Lumbricos } \\
\text { tineasque } \\
\text { solet, si trita } \\
\text { bibatur / } \\
\text { Cum vino } \\
\text { vel si mixto } \\
\text { sumatur } \\
\text { aceto. }\end{array}$ & $\begin{array}{l}\text { [52rb] E } \\
\text { dize Galieno } \\
\text { que esta } \\
\text { yerva ha tal } \\
\text { virtud, que } \\
\text { si es bevida } \\
\text { con vino o } \\
\text { con vinagre, } \\
\text { mata las } \\
\text { lonbrizes e } \\
\text { las tiñas. }\end{array}$ & & $\begin{array}{l}\text { [13vb] E } \\
\text { dize Galieno } \\
\text { que si el } \\
\text { çumo del es } \\
\text { beujdo con } \\
\text { vjno o con } \\
\text { vjnagre } \\
\text { mata las } \\
\text { lonbrjzes. }\end{array}$ & & \\
\hline
\end{tabular}

32 «Los dos extractos, a parte de la diferencia de las lenguas, son prácticamente idénticos desde el punto de vista léxico y sintáctico. (...) La similitud entre los dos trozos (que se observa a lo largo de todo el texto) indica que no se puede tratar aquí de dos traducciones independientes, sino de una misma tradición textual con un antecedente común que no puede ser el texto latino original en verso. La pregunta a plantearse en el marco de la edición de estos manuscritos es, naturalmente, qué relación exacta tienen entre sí. (...) Resumiendo los resultados de este apartado, se puede decir que las versiones iberorrománicas del Macer Floridus pertenecen a una misma tradición en prosa, y se ve claramente que se trata de traducciones de unos manuscritos a otros». Guido Mensching, «El Macer Floridus...», cit., pág. 98. 


\begin{tabular}{|c|c|c|c|c|c|}
\hline $\begin{array}{l}\text { Macer } \\
\text { latino }\end{array}$ & $Z$ & $M A C$ & $S D M$ & $K$ & $E$ \\
\hline $\begin{array}{l}\text { (vv. 1607- } \\
1609) \\
\text { Splen, iecur } \\
\text { et renes cum } \\
\text { mulsa } \\
\text { sumpta } \\
\text { iuvabit, / Si } \\
\text { iungatur ei } \\
\text { violenter } \\
\text { amygdala } \\
\text { trita, / } \\
\text { Menstrua } \\
\text { sic purgat et } \\
\text { fluxum } \\
\text { detinet alvi. }\end{array}$ & $\begin{array}{l}\text { [60ra] La } \\
\text { peonía ha tal } \\
\text { virtud, que } \\
\text { es caliente e } \\
\text { seca. E si es } \\
\text { majada con } \\
\text { almendras e } \\
\text { bevida con } \\
\text { agua o con } \\
\text { vino, } \\
\text { aprovecha al } \\
\text { esplén e al } \\
\text { vientre e a } \\
\text { las renes e } \\
\text { purga la } \\
\text { sobejana } \\
\text { sangre de la } \\
\text { muger. }\end{array}$ & $\begin{array}{l}{[16 \mathrm{v}] \text { Peonja }} \\
\text { es vna yerua } \\
\text { que dizen los } \\
\text { menges que } \\
\text { es caljente de } \\
\text { natura Et A } \\
\text { atal virtud } \\
\text { que sy es } \\
\text { pisada con } \\
\text { almendras Et } \\
\text { beujda con } \\
\text { agua o con } \\
\text { vjno } \\
\text { Aprouecha } \\
\text { mucho al } \\
\text { esplen Et al } \\
\text { vjentre \& a } \\
\text { las arterias Et } \\
\text { purga la } \\
\text { muchedunbre } \\
\text { de la sangre } \\
\text { de la muger. }\end{array}$ & $\begin{array}{l}\text { [14ra] } \\
\text { Otrosy, la } \\
\text { peonja } \\
\text { pisada con } \\
\text { almendras \& } \\
\text { beujda con } \\
\text { agua o con } \\
\text { vjno, } \\
\text { aprouecha } \\
\text { mucho al } \\
\text { espien \& al } \\
\text { vientre \& } \\
\text { renes \& } \\
\text { purga } \\
\text { sobejanja de } \\
\text { la sangre de } \\
\text { la muger. }\end{array}$ & & \\
\hline $\begin{array}{l}\text { (vv. 1494- } \\
\text { 1495) } \\
\text { Movet } \\
\text { urinam, } \\
\text { depellit } \\
\text { abortum, / } \\
\text { Dicitur haec } \\
\text { eadem } \\
\text { stipatum } \\
\text { solvere } \\
\text { ventrem. }\end{array}$ & $\begin{array}{l}\text { [44ra] E ha } \\
\text { otra virtud, } \\
\text { que faze } \\
\text { mear } \\
\text { aquéllos que } \\
\text { non pueden } \\
\text { bien mear. E } \\
\text { faze sallir la } \\
\text { criatura } \\
\text { muerta del } \\
\text { vientre e } \\
\text { faze bien } \\
\text { sallir. }\end{array}$ & $\begin{array}{l}{[2 \mathrm{v}] \text { \& faz }} \\
\text { bien mear Et } \\
\text { faze saljr la } \\
\text { criatura } \\
\text { muerta del } \\
\text { vientre Et } \\
\text { faze bien } \\
\text { saljr a } \\
\text { camara. }\end{array}$ & $\begin{array}{l}\text { [14rb] Otra } \\
\text { virtud, que } \\
\text { faze bien } \\
\text { mear \& faze } \\
\text { a la muger } \\
\text { echar la } \\
\text { criatura } \\
\text { muerta del } \\
\text { vientre \& } \\
\text { faze bien } \\
\text { salir a } \\
\text { camara. }\end{array}$ & $\begin{array}{l}{[169 \mathrm{v}-170 \mathrm{r}]} \\
\text { e faze vien } \\
\text { sallir a } \\
\text { cámara. }\end{array}$ & $\begin{array}{l}{[79 v] \text { Y mas }} \\
\text { tiene otra } \\
\text { virtud, que } \\
\text { haze mear } \\
\text { aquellos que } \\
\text { no pueden } \\
\text { bien mear y } \\
\text { faze salir la } \\
\text { criatura } \\
\text { muerta del } \\
\text { vientre y } \\
\text { haze bien } \\
\text { saljr a } \\
\text { camara al } \\
\text { hombre que } \\
\text { no puede } \\
\text { bien saljr. }\end{array}$ \\
\hline
\end{tabular}

\begin{tabular}{|c|c|c|}
\hline Macer latino & $F$ & $S D M$ \\
\hline $\begin{array}{l}(v v .2093-2096) \\
\text { Non modicum prodest } \\
\text { sumptum cum melle caducis, } \\
\text { / Sicque levare solet } \\
\text { morbum qui membra } \\
\text { resolvit; } \\
\text { Suspensum collo pueris } \\
\text { prodesse caducis / Creditur } \\
\text { et solo succurrere fertur } \\
\text { odore. }\end{array}$ & $\begin{array}{l}\text { [58c] Item, si prens } \\
\text { longament lo pelitre ab mel, } \\
\text { profita molt a la gota qi fa } \\
\text { caure e profita molt als } \\
\text { infants qi cahen de gota si } \cdot 1 \\
\text { porten al coyl ligat, e tira la } \\
\text { olor per les narils. }\end{array}$ & $\begin{array}{l}\text { [14rb] Otrosi, si vsas mucho } \\
\text { el pelitre con la mjel } \\
\text { aprouecha mucho a la gota } \\
\text { que derriba si la lleua al } \\
\text { cuello ligada \& olerla por } \\
\text { las narizes. }\end{array}$ \\
\hline $\begin{array}{l}(v v .2102-2103) \\
\text { Unguine si totum corpus } \\
\text { mulcebitur isto, / Largos per } \\
\text { poros sudor procedet } \\
\text { apertos. }\end{array}$ & $\begin{array}{l}\text { [58c] Item, ha altra vertut } \\
\text { aquest oli : que, si hon } \\
\text { [hom] no pot suar, tantost } \\
\text { suarà e ab la suor perdrà la } \\
\text { dolor. }\end{array}$ & $\begin{array}{l}\text { [14rb] E eso mesmo el que } \\
\text { non puede sudar vntese con } \\
\text { [14va] este oleo \& sudara. }\end{array}$ \\
\hline
\end{tabular}


Entre todos estos pasajes sobresale uno que anula cualquier reticencia sobre la relación entre los textos analizados. La última virtud que aparece en este manuscrito, correspondiente al PYRETHRUM, presenta un error que ahora sabemos común al texto en castellano y en catalán:

\begin{tabular}{|c|c|c|}
\hline Macer latino & $F$ & $S D M$ \\
\hline $\begin{array}{l}\text { (2109-2110) } \\
\text { Gingiber atque piper } \\
\text { aequales in medicina/ } \\
\text { Dicunt, hac causa taceo de } \\
\text { viribus eius. }\end{array}$ & $\begin{array}{l}\text { E sàpies per sert que totes } \\
\text { aquelles vertuts e totes } \\
\text { aquelles forses que ha lo } \\
\text { pelitre, aquelles mateixes ha } \\
\text { lo gingebre, e per asò no te·n } \\
\text { vuyl plus parlar. }\end{array}$ & $\begin{array}{l}\text { [14va] E estas mesmas } \\
\text { virtudes ha el gengibre que } \\
\text { ha el pelitre. }\end{array}$ \\
\hline
\end{tabular}

Ya Thomas Capuano ${ }^{33}$ había llamado la atención sobre el error de atribuir al «gengibre» las virtudes del «pelitre», mientras que el texto latino relaciona el GINGIBER con el PIPER (pimienta):

The Latin chapter 68, «Gingiber», consists of just two verses, 2109-2110 (Macer latino 1832, 116). These were mistranslated and attached to the end of chapter 63 in Barberá, 67 in Faraúdo.

El error denunciado por Capuano para los textos catalanes - consecuencia quizás de la posición del GINGIBER tras el PYRETHRUM y no tras el PIPER-, figura también en SDM. Éste es indicio claro de que tal deturpación podría figurar ya en un estadio bastante primitivo de la transmisión textual, acaso en la primera traducción del latín al romance peninsular. En todo caso, el pasaje permite conjeturar con fundamento que existe una relación directa entre el texto del manuscrito RB II-3063 y las demás versiones peninsulares del Macer Floridus.

A pesar de esta certidumbre, los pasajes de SDM no pueden ser considerados paradigmáticos en un estudio de la difusión del herbario latino, pues también presentan problemas de difícil explicación, ligados a una transmisión textual defectuosa. Además del aparente desorden en la disposición de las plantas, la cuestión más llamativa es la del título de dos capítulos de este conjunto. En todos ellos se describe una planta concreta, manteniendo en general la misma disposición de virtudes que las demás versiones romances del herbario; pero se observan dos epígrafes espurios para los capítulos de la PAEONIA y del PYRETHRUM. En efecto, en ambos casos el capítulo presenta un título que hace referencia, no al nombre de la planta, sino a una dolencia particular: «la gota que derriba» $\mathrm{y}$ «el dolor de dientes», respectivamente. Tras tales epígrafes se encuentra la descripción de otras propiedades de cada planta concreta, además de la que sirve de título al capítulo. Es el caso del pasaje que inicia las virtudes de la PAEONIA:

33 Thomas M. Capuano, «Medieval iberian...», cit., pág. 201. 


\begin{tabular}{|c|c|c|c|}
\hline Macer latino & $Z$ & $M A C$ & $S D M$ \\
\hline $\begin{array}{l}\text { (vv. 1617-1618) } \\
\text { Illius radix pueris } \\
\text { suspensa caducis / } \\
\text { Non modicum } \\
\text { prodest }\end{array}$ & $\begin{array}{l}\text { [60ra] Et A otra } \\
\text { virtud la rrays della } \\
\text { que sy es atada al } \\
\text { cuello delybra aquel } \\
\text { que cahe de gota. }\end{array}$ & $\begin{array}{l}\text { [16v] Et sy la rrayz } \\
\text { della es colgada al } \\
\text { cuello sana \& } \\
\text { delibra a aquellos } \\
\text { que caen de gota. }\end{array}$ & $\begin{array}{l}\text { [14ra] Para la gota } \\
\text { que derriba. Toma la } \\
\text { peonja \& atala al } \\
\text { cuello del enfermo. }\end{array}$ \\
\hline $\begin{array}{l}\text { (vv. 1607-1609) } \\
\text { Splen, iecur et renes } \\
\text { cum mulsa sumpta } \\
\text { iuvabit, / Si iungatur } \\
\text { ei violenter } \\
\text { amygdala trita, / } \\
\text { Menstrua sic purgat } \\
\text { et fluxum detinet } \\
\text { alvi. }\end{array}$ & $\begin{array}{l}\text { [60ra] La peonía ha } \\
\text { tal virtud, que es } \\
\text { caliente e seca. E si } \\
\text { es majada con } \\
\text { almendras e bevida } \\
\text { con agua o con vino, } \\
\text { aprovecha al esplén } \\
\text { e al vientre e a las } \\
\text { renes e purga la } \\
\text { sobejana sangre de } \\
\text { la muger. }\end{array}$ & $\begin{array}{l}\text { [16v] Peonja es vna } \\
\text { yerua que dizen los } \\
\text { menges que es } \\
\text { caljente de natura Et } \\
\text { A atal virtud que sy } \\
\text { es pisada con } \\
\text { almendras Et beujda } \\
\text { con agua o con vjno } \\
\text { Aprouecha mucho al } \\
\text { esplen Et al vjentre } \\
\& \text { a las arterias Et } \\
\text { purga la } \\
\text { muchedunbre de la } \\
\text { sangre de la muger. }\end{array}$ & $\begin{array}{l}\text { [14ra] Otrosy, la } \\
\text { peonja pisada con } \\
\text { almendras \& beujda } \\
\text { con agua o con vjno, } \\
\text { aprouecha mucho al } \\
\text { espien \& al vientre } \\
\text { \& renes \& purga } \\
\text { sobejanja de la } \\
\text { sangre de la muger. }\end{array}$ \\
\hline
\end{tabular}

Este capítulo de la PAEONIA de SDM presenta una alteración del orden de las recetas, pero no es óbice para comprobar que se recogen virtudes no sólo para el bazo, sino también para el vientre, los riñones y la menstruación excesiva.

En el capítulo del PYRETHRUM, aparecen virtudes contra el dolor de dientes, como indica su título, pero también para tratar afecciones de garganta y lengua ${ }^{34}$.

\begin{tabular}{|c|c|c|}
\hline Macer latino & $F$ & $S D M$ \\
\hline $\begin{array}{l}\text { (2086-2092) } \\
\text { Est Pyrethrum calidum } \\
\text { siccumque, quartus in istis / } \\
\text { Est gradus; excruciat dentes } \\
\text { si frigidus humor } \\
\text { Masticet hoc patiens, } \\
\text { teneatque diutius ore, / Et } \\
\text { iuvat admixto si } \\
\text { gargarizetur aceto; / } \\
\text { Hocque modo tumidam } \\
\text { reprimit de flegmate } \\
\text { linguam, / Sic uvam relevat } \\
\text { humoris pondere pressam, / } \\
\text { Et multis aliis vitiis sic } \\
\text { subvenit oris. }\end{array}$ & $\begin{array}{l}\text { [58b] Del pelitre.- Pelitre és } \\
\text { calent e sech, e, si hom ha } \\
\text { dolor per fret en les dents e } \\
\text { prens lo pelitre e } \cdot 1 \text { mastega } \\
\text { molt bé entre les dents e } \\
\text { depuys se lava la bocha ab } \\
\text { vinagre, sana la infladura de } \\
\text { la garganta [58c] e la } \\
\text { infladura de la lengua. }\end{array}$ & $\begin{array}{l}\text { [14rb] Virtudes para el dolor } \\
\text { delos dientes. Toma el } \\
\text { pelitre \& maxcalo bien con } \\
\text { los dientes \& despues laua la } \\
\text { boca con vjnagre fasta que } \\
\text { faga espuma \& sanaras. E } \\
\text { esto mesmo faras para la } \\
\text { finchadura de la gulilla \& de } \\
\text { la [r]ubilla \& de la } \\
\text { hinchadura de la lengua. }\end{array}$ \\
\hline
\end{tabular}

${ }^{34}$ Este pasaje también es llamativo porque el castellano presenta más fidelidad al texto latino que el catalán, al distinguir correctamente las virtudes para los dientes y aquéllas para la garganta y la lengua, separándolas con la coda habitual «\& sanaras». Las versiones catalanas fusionan ambas virtudes en una sola, indivisible, revelando una posible deturpación textual o una pequeña laguna. 
No parece posible aventurar ninguna hipótesis para esta variación en los títulos; se podría conjeturar un cambio de estrategia en la disposición textual del autor-copista, abandonando la distribución por plantas para preferir una presentación por dolencias. No obstante, no se encuentra un epígrafe para cada afección. Además, entre las virtudes de la PAEONIA y del PYRETHRUM figura el capítulo de la ENULA, indicándose en el título, no ya una posible afección, sino el nombre de la planta: «Virtudes del ala». La presentación aparentemente aleatoria de estos pasajes hace difícil, por el momento, cualquier hipótesis plausible.

La brevedad del texto de $S D M$ no impide observar en él características particulares frente a las demás obras del corpus peninsular del Macer Floridus. Por ejemplo, en la descripción de las virtudes del CORIANDRUM se observa que $S D M$ corrige una clara deturpación del códice Zabálburu y presenta una variante textual distinta de la que figura en catalán:

\begin{tabular}{|c|c|c|c|}
\hline Macer latino & $Z$ & $F$ & $S D M$ \\
\hline $\begin{array}{l}\text { (vv. 962-963) } \\
\text { Uva cum passa } \\
\text { Coriandrum melque } \\
\text { iugatum / Sedabunt } \\
\text { varios superaddita } \\
\text { trita tumores. }\end{array}$ & $\begin{array}{l}\text { [52rb] E ha otra } \\
\text { virtud, que si es } \\
\text { mezclada con uva } \\
\text { pasa o con miel e es } \\
\text { bien majada, tuelle } \\
\text { el dolor [del } \\
\text { vientre]. }\end{array}$ & $\begin{array}{l}\text { [26a] Item, si és } \\
\text { picada ab panses e } \\
\text { ab mel, toll totes } \\
\text { dolors }\end{array}$ & $\begin{array}{l}\text { [13vb] Otrosy, sy lo } \\
\text { mesclas con vinagre } \\
\& \text { con mjel \& sea } \\
\text { bien pisada \& } \\
\text { beujda quita todo } \\
\text { dolor de todos los } \\
\text { mjenbros. }\end{array}$ \\
\hline
\end{tabular}

Aunque SDM presenta una divergencia importante en la primera parte del pasaje, que trataré más adelante, su texto aplica esta receta al «dolor de todos los mjenbros», frente al «dolor del vientre», de Z. Por su parte, los textos catalanes presentan un texto más genérico, «totes dolors», que mantiene el sentido «varios... tumores», del latín. Esta variación indica que la deturpación de $Z$ es propia de este manuscrito, o tal vez de su familia de transmisión, pero no de la traducción castellana.

Debido probablemente a su brevedad, $S D M$ se atiene, en general, a una estructura más formularia que las demás versiones peninsulares, según se desprende de los siguientes pasajes:

\begin{tabular}{|c|c|c|c|}
\hline Macer latino & $Z$ & $M A C$ & $S D M$ \\
\hline $\begin{array}{l}\text { (1945-1947) } \\
\text { Ore diu tepidum si } \\
\text { contineatur acetum, } \\
\text { / Quo sint decoctae } \\
\text { radices illius } \\
\text { herbae, / Dicitur } \\
\text { immodicum dentis } \\
\text { placare dolorem. }\end{array}$ & & $\begin{array}{l}{[21 \mathrm{v}] \text { Et sy tomas }} \\
\text { las rrayzes o la } \\
\text { symjente \& la } \\
\text { cuezes bien en } \\
\text { vjnagre \& la pones } \\
\text { en la boca aquel } \\
\text { vjnagre \& lo } \\
\text { mezclas tanto que lo } \\
\text { fagas espumar Et } \\
\text { despues echas el } \\
\text { vjnagre do vieres el } \\
\text { mal doljente el } \\
\text { diente sanara. }\end{array}$ & $\begin{array}{l}\text { [13va] Otrosy, toma } \\
\text { la semjente \& la } \\
\text { rayz desta dicha } \\
\text { yerua \& cuezelo con } \\
\text { vinagre \& metelo en } \\
\text { la boca fasta que } \\
\text { faga espuma \& } \\
\text { sanara el diente que } \\
\text { duele. }\end{array}$ \\
\hline
\end{tabular}




\begin{tabular}{|c|c|c|c|}
\hline Macer latino & $Z$ & $M A C$ & $S D M$ \\
\hline $\begin{array}{l}\text { (vv. 1610-1613) } \\
\text { Illius in vino } \\
\text { decoctio saepius } \\
\text { hausta / Vesicae } \\
\text { duros sedat sic } \\
\text { sumpta dolores, / Et } \\
\text { scotosim sic illa } \\
\text { iuvat stomachique } \\
\text { dolorem, / } \\
\text { Nefreticos eadem } \\
\text { multum iuvat, } \\
\text { ictericosque. }\end{array}$ & $\begin{array}{l}\text { [60ra] E ha otra } \\
\text { virtut, que si es } \\
\text { cocha con vino e es } \\
\text { bevida, aprovecha } \\
\text { mucho al dolor de la } \\
\text { coxa e al dolor de la } \\
\text { bexiga e al dolor del } \\
\text { vientre e <a> } \\
\text { aquéllos que han } \\
\text { mal en las renes e a } \\
\text { los que han la tos. }\end{array}$ & $\begin{array}{l}\text { [16v] Et sy es cocha } \\
\text { con vjno \& es } \\
\text { beujda aprouecha } \\
\text { mucho al dolor de la } \\
\text { pierrna Et al dolor } \\
\text { de la bexiga \& al } \\
\text { dolor del vientre Et } \\
\text { aquellos que an } \\
\text { malas orynas Et } \\
\text { aquellos que an tos. }\end{array}$ & $\begin{array}{l}\text { [14ra] Yten, sy esta } \\
\text { yerua es cocha con } \\
\text { vjno \& beues della, } \\
\text { aprouecha al dolor } \\
\text { de la vexiga \& de } \\
\text { las renes. }\end{array}$ \\
\hline
\end{tabular}

\begin{tabular}{|l|l|l|}
\hline Macer latino & $F$ & SDM \\
\hline $\begin{array}{l}\text { (vv. 2097-2098) } \\
\begin{array}{l}\text { Ex oleo quo decoquitur si } \\
\text { morpus inungas / Ante febris } \\
\text { motum, minuet tolletque } \\
\text { rigorem. }\end{array}\end{array}$ & $\begin{array}{l}\text { [58c] Item, si hom qi ha la } \\
\text { febra se unta ab l'oli hon lo } \\
\text { pelitre serà cuyt ans que·1 } \\
\text { prena, sàpies que sanarà, } \\
\text { que fer-l'à suar e ab la suor } \\
\text { perdrà la febra. }\end{array}$ & $\begin{array}{l}\text { [14rb] Otrosy, qual quier } \\
\text { omne que aya fiebre cuega } \\
\text { el pelitre con oleo \& vntese } \\
\text { con el \& sanara. }\end{array}$ \\
\hline $\begin{array}{l}\text { (vv. 2100-2101) } \\
\text { Miram sentit opem } \\
\text { paralyticus inde perunctus, / } \\
\text { Non leviter manibus fuerit si } \\
\text { saepe fricatus. }\end{array}$ & $\begin{array}{l}\text { [58c] Item, aquest oli val } \\
\text { que, si hon [hom] ha gran } \\
\text { dolor e se·n unta ben fregan } \\
\text { moltes vegades, ho que sia } \\
\text { ferit de paralis, sàpies que li } \\
\text { farà profit. }\end{array}$ & $\begin{array}{l}\text { [14rb] E vntese con ese [con } \\
\text { ele } \text { oleo el que ha perlesia }\end{array}$ \\
\hline
\end{tabular}

El más llamativo es el que narra la anécdota de Galeno, momento central en la descripción de la PAEONIA tanto en latín como en las versiones castellana y catalana, que en $S D M$ es eliminado y sustituido por una coda formularia:

\begin{tabular}{|c|c|c|c|}
\hline Macer latino & $Z$ & $M A C$ & $S D M$ \\
\hline $\begin{array}{l}\text { (vv. 1618-1627) } \\
\text { Galienus ut asserit } \\
\text { auctor; / Quendam } \\
\text { se puerum narrat } \\
\text { vidisse caducum, / } \\
\text { etas cuius erat } \\
\text { annorum circiter } \\
\text { octo, / Paeoniae } \\
\text { puer hic radicem } \\
\text { ferre solebat / A } \\
\text { ppensam collo; } \\
\text { quadam vice decidit } \\
\text { illa, / Moxque puer } \\
\text { cecidit, solito qua } \\
\text { more ligata / } \\
\text { Protinus evasit; }\end{array}$ & $\begin{array}{l}\text { [60ra] E esto es } \\
\text { verdat, que Galieno } \\
\text { lo provó en tal } \\
\text { guisa: vido una vez } \\
\text { un mançebo de } \\
\text { tierra de oriente que } \\
\text { traíe por aventura la } \\
\text { raíz de la peonía } \\
\text { atada al cuello. Este } \\
\text { mançebo podía aver } \\
\text { [días e] ocho años e } \\
\text { podía aver por } \\
\text { aventura que aquella } \\
\text { raíz se le cayó del } \\
\text { cuello e el mançebo } \\
\text { cayó luego en tierra }\end{array}$ & $\begin{array}{l}\text { [16v] Et esto es } \\
\text { verdat que galieno } \\
\text { lo prouo en tal } \\
\text { manera vio vn moço } \\
\text { que podia auer ocho } \\
\text { años en tierra de } \\
\text { oriente \& leuaua la } \\
\text { rrayz de la peonja } \\
\text { atada al cuello \& } \\
\text { vjno por } \\
\text { desauentura que se } \\
\text { desato \& cayo el } \\
\text { moço en tierra } \\
\text { porque auja gota Et } \\
\text { con tanto tomo la } \\
\text { verua galjeno Et }\end{array}$ & $\begin{array}{l}\text { [14rb] E esto es cosa } \\
\text { prouada \& çierta. }\end{array}$ \\
\hline
\end{tabular}




\begin{tabular}{|c|c|c|}
\hline $\begin{array}{l}\text { Galienus vero } \\
\text { probare / Rem plene } \\
\text { cupiens radicem } \\
\text { denuo dempsit / De } \\
\text { collo pueri, cecidit, } \\
\text { viguitque resumpta; } \\
\text { / Cognita vis herbae } \\
\text { fuit huius sic } \\
\text { manifeste. }\end{array}$ & $\begin{array}{l}\text { de la gota. E } \\
\text { Galieno tomó luego } \\
\text { la yerva e atógela al } \\
\text { cuello e tan aína } \\
\text { como la ovo atada, } \\
\text { levantose luego el } \\
\text { mançebo. E por } \\
\text { mejor le provar, } \\
\text { tollole otra vez la } \\
\text { yerva del cuello e } \\
\text { luego cayó en tierra. } \\
\text { E después atógela } \\
\text { otra vez e levantose } \\
\text { el mançebo. E en } \\
\text { esto lo provó e vido } \\
\text { que verdat era la } \\
\text { virtud desta yerva. }\end{array}$ & $\begin{array}{l}\text { atola al moço al } \\
\text { cuello \& luego se } \\
\text { leuanto \& por la } \\
\text { mejor prouar } \\
\text { desatogela con de } \\
\text { cabo \& luego cayo /. } \\
\text { el moço con de cabo } \\
\text { en tierra Et despues } \\
\text { atole galjeno la } \\
\text { yerua al cuello otra } \\
\text { vegada \& leuantose } \\
\text { el moço luego \& } \\
\text { fuese su via Et asy } \\
\text { prouo que era verdat } \\
\text { la yerua en esta } \\
\text { virtud. }\end{array}$ \\
\hline
\end{tabular}

No parece que tal ausencia se deba a una laguna textual, sino al interés eminentemente práctico que se terminó otorgando al herbario, en el que se optó por eliminar cualquier elemento que no fuera esencial para la transmisión del saber médico. Lo mismo sucede en la descripción del PYRETHRUM, ya mencionada (vid. supra, vv. 2097-2098), en la que la proposición de la versión catalana «e ab la suor perdrà la febra» es también sustituida por un simple «sanara», sin que el sentido general de la receta se vea afectado. Tales variaciones textuales, conscientes, permiten emitir la hipótesis de que la versión de $S D M$ es posterior a los demás textos castellanos conocidos, tal vez surgida tras una reelaboración textual poco profunda.

Algunas variaciones léxicas de $S D M$ indican, asimismo, que nos hallamos posiblemente ante un texto más reciente que las versiones de $Z$ y de $M A C^{35}$. No es así en la mayoría de los casos, en los que los cambios léxicos son comunes y poco llamativos:

\begin{tabular}{|c|c|c|c|}
\hline Macer latino & $Z$ & $M A C$ & $S D M$ \\
\hline $\begin{array}{l}\text { (vv. 1951-1954) } \\
\text { Seminis illius obolus } \\
\text { cum semine mixtus / } \\
\text { Miconis pariter cum } \\
\text { mulsa sumitur illis / } \\
\text { Utiliter, fluxum } \\
\text { matricis quae } \\
\text { patiuntur, / Et } \\
\text { dicunt haemoptoicis } \\
\text { sic posse mederi. }\end{array}$ & & $\begin{array}{l}{[21 \mathrm{v}] \text { Et sepas que }} \\
\text { sy la muger toma el } \\
\text { çumo de lla } \\
\text { symjente \& la pone } \\
\text { en su natura estanca } \\
\text { al fluxo sangujs. }\end{array}$ & $\begin{array}{l}\text { [13va] Otrosy, toma } \\
\text { el çumo desta dicha } \\
\text { yerua \& echalo } \\
\text { dentro en la natura } \\
\text { de la muger \& } \\
\text { estañarle ha la } \\
\text { sangre luuja. }\end{array}$ \\
\hline
\end{tabular}

${ }^{35}$ Más difícil es establecer hipótesis para textos tan breves como $K$ y $E$. 


\begin{tabular}{|c|c|c|c|}
\hline Macer latino & $Z$ & $M A C$ & $S D M$ \\
\hline $\begin{array}{l}\text { (v. } 964) \\
\text { Praecipue testes } \\
\text { tumidos iuvat hoc } \\
\text { medicamen. }\end{array}$ & $\begin{array}{l}\text { [52rb] E esta } \\
\text { confeçión [52va] es } \\
\text { muy provechosa a la } \\
\text { finchadura de los } \\
\text { genitarios. }\end{array}$ & & $\begin{array}{l}\text { [13va] E esta } \\
\text { confaçion es mucho } \\
\text { prouechosa para la } \\
\text { finchazon de los } \\
\text { conpañones. }\end{array}$ \\
\hline $\begin{array}{l}\text { (vv.965-966) } \\
\text { Illius semen ventrem } \\
\text { stipare solutum / } \\
\text { Fertur, aquae } \\
\text { iunctum fuerit si } \\
\text { saepius haustam. }\end{array}$ & $\begin{array}{l}\text { [52va] E ha otra } \\
\text { virtut, que si la } \\
\text { simiente della fuere } \\
\text { molida e bevida } \\
\text { muchas vezes, faze } \\
\text { estancar la menazón. }\end{array}$ & & $\begin{array}{l}\text { [13vb] Otrosy, la } \\
\text { semjente desta yerua } \\
\text { molida \& beujda } \\
\text { muchas vezes con } \\
\text { agua estaña la } \\
\text { corrençia. }\end{array}$ \\
\hline $\begin{array}{l}\text { (vv. 976-978) } \\
\text { Huic succo si iuncta } \\
\text { fabae sit sola farina } \\
\text { / Et superaddatur } \\
\text { scrophis } \\
\text { medicabitur illis } \\
\text { Et cede fervens } \\
\text { emplastro pustula } \\
\text { tali. }\end{array}$ & $\begin{array}{l}\text { [52va] E ha otra } \\
\text { virtut, que si el } \\
\text { çumo della es } \\
\text { mezclado con farina } \\
\text { de ordio e puesto } \\
\text { sobre los porçiellos } \\
\text { que se fazen } \\
\text { aderredor del cuello, } \\
\text { sánalos. }\end{array}$ & & $\begin{array}{l}\text { [13vb] Otra virtud, } \\
\text { que sy el çumo desta } \\
\text { yerua es mezclado } \\
\text { con farina de ordio } \\
\& \text { puesto sobre las } \\
\text { postillas, sanalas, \& } \\
\text { las señales \& } \\
\text { enpeynes que } \\
\text { nasçen en el } \\
\text { pescueço. }\end{array}$ \\
\hline
\end{tabular}

$S D M$ sustituye en estos pasajes «genitarios» por «compañones», «menazón» por «corrençia» o «porçiellos» por «empeines». En estos casos, la elección léxica de cada texto impide incluso discernir cuál es la versión más antigua, al igual que sucede en la elección verbal en los siguientes pasajes:

\begin{tabular}{|l|l|l|l|}
\hline Macer latino & $Z$ & MAC & SDM \\
\hline $\begin{array}{l}\text { (vv. 1615-1616) } \\
\text { Pressuras, } \text { inferre } \\
\text { solent quas somnia } \\
\text { nocte, / Paeoniae } \\
\text { sement, bibitur si } \\
\text { saepius, arcet. }\end{array}$ & $\begin{array}{l}\text { [60ra] E si es bevida } \\
\text { muchas vezes con } \\
\text { agua o con vino, } \\
\text { encalça la fantasma } \\
\text { que es dicha } \\
\text { pesadilla, que suele } \\
\text { apremiar a los niños. }\end{array}$ & $\begin{array}{l}\text { [16v \& sy es beujda } \\
\text { o comjda muchas } \\
\text { vezes alcança la } \\
\text { pesada que suele } \\
\text { tomar a los omnes } \\
\text { quando duermen. }\end{array}$ & $\begin{array}{l}{[14 \mathrm{ra}] \text { E si es beujda }} \\
\text { muchas vezes con } \\
\text { agua o con vjno } \\
\text { espanta la fantasma, } \\
\text { la que suele pesar, } \\
\text { que dizen la } \\
\text { manpesadilla. }\end{array}$ \\
\hline $\begin{array}{l}\text { (vv. 1617-1618) } \\
\text { Illius radix pueris } \\
\text { suspensa caducis / } \\
\begin{array}{l}\text { Non modicum } \\
\text { prodest. }\end{array}\end{array}$ & $\begin{array}{l}\text { 60ra] E ha otra } \\
\text { virtud la raíz della, } \\
\text { que si es atada al } \\
\text { cuello, delibra aquél } \\
\text { que cahe de gota. }\end{array}$ & $\begin{array}{l}{[16 \mathrm{v}] \text { Et sy la rrayz }} \\
\text { della es colgada al } \\
\text { cuello sana \& } \\
\text { delibra a aquellos } \\
\text { que caen de gota. }\end{array}$ & $\begin{array}{l}{[14 \mathrm{rb}] \text { Otrossi, sy la }} \\
\text { rayz della es ligada } \\
\text { al cuello aljuja a los } \\
\text { que caen de gota. }\end{array}$ \\
\hline
\end{tabular}

Entre estas divergencias cabe destacar las descripciones de las dos primeras virtudes de la ENULA, las únicas del Macer Floridus de las que se conservan cinco versiones castellanas completas. La primera de ellas, en particular, presenta cinco variantes distintas del vocablo latino MENSTRUA: «multitudo sanguinis», «muchedunbre de la muger», «sangre mucha», «mucha sangre»y «sangre»: 


\begin{tabular}{|c|c|c|c|c|c|}
\hline Macer latino & $Z$ & $M A C$ & $S D M$ & $\bar{K}$ & $E$ \\
\hline $\begin{array}{l}\text { (v. } 1493- \\
\text { 1494) } \\
\text { Illius } \\
\text { decoctio } \\
\text { menstrua } \\
\text { purgat / Si } \\
\text { bibitur. }\end{array}$ & $\begin{array}{l}\text { [44ra] El ala } \\
\text { ha tal virtud, } \\
\text { que si es } \\
\text { cocha en } \\
\text { agua e } \\
\text { aquella agua } \\
\text { es bevida, } \\
\text { faze estancar } \\
<\text { la }> \\
\text { multitudo } \\
\text { sanguinis } \\
\text { quando ha su } \\
\text { flor la } \\
\text { muger. }\end{array}$ & $\begin{array}{l}\text { [2v] Capitulo } \\
. v . \text { de las } \\
\text { virtudes de } \\
\text { vna yerua } \\
\text { que es dicha } \\
\text { ala Ala es } \\
\text { vna yerua } \\
\text { muy buena \& } \\
\text { la su propia } \\
\text { virtud es } \\
\text { buena que sy } \\
\text { es cocha con } \\
\text { agua \& aquel } \\
\text { agua es } \\
\text { beujda faze } \\
\text { estancar la } \\
\text { muchedunbre } \\
\text { de la muger } \\
\text { quando la ha } \\
\text { de floreza. }\end{array}$ & $\begin{array}{l}{[14 \mathrm{vb}]} \\
\text { Virtudes del } \\
\text { ala. Si la } \\
\text { cozieres con } \\
\text { agua fazerte } \\
\text { ha estancar } \\
\text { la sangre } \\
\text { mucha a la } \\
\text { muger. }\end{array}$ & $\begin{array}{l}\text { [169v-170] } \\
\text { Esta es la } \\
\text { primera } \\
\text { vertud del } \\
\text { ala si es } \\
\text { cocha en } \\
\text { augua e das } \\
\text { aquella agua } \\
\text { a veuer a la } \\
\text { muger : } \\
\text { estanca la } \\
\text { mucha } \\
\text { sangre } \\
\text { quando ha su } \\
\text { flor. }\end{array}$ & $\begin{array}{l}{[79 \mathrm{v}] \text { Sy el }} \\
\text { ala es cocha } \\
\text { en agua y } \\
\text { aquella agua } \\
\text { es bebida, } \\
\text { restriñe la } \\
\text { sangre } \\
\text { quando le } \\
\text { viene su flor } \\
\text { a la muger. }\end{array}$ \\
\hline
\end{tabular}

A estas versiones se añade la catalana «multitut de la sanch», que tampoco tiene correspondencia literal en castellano; por consiguiente, no es posible deducir en el estadio actual de la investigación, cuál sería la opción que figuraba en la primera traducción al romance.

Aunque la incertidumbre es grande y parece difícil establecer alguna conclusión, hay un pasaje que induce a sospechar que la versión de SDM presenta un texto posterior y modificado con respecto a la hipotética primera versión en castellano:

\begin{tabular}{|c|c|c|}
\hline Macer latino & $M A C$ & $S D M$ \\
\hline $\begin{array}{l}\text { (vv. 1940-1941) } \\
\text { Iusquiami foliis contritis } \\
\text { adde polentam, / Haec } \\
\text { adhibendo potes quosvis } \\
\text { curare tumores. }\end{array}$ & $\begin{array}{l}\text { [21v] capitulo lxxij. de las } \\
\text { virtudes de veleño Ueleño es } \\
\text { de fria natura Et es la } \\
\text { primera virtud del atal que } \\
\text { sy la pisas las fojas \& las } \\
\text { Ayuntas con faryna de } \\
\text { ordio \& las fazes enplasto \& } \\
\text { las pones sobre la } \\
\text { finchadura desfazela. }\end{array}$ & $\begin{array}{l}\text { [13va] Virtudes del veleño. } \\
\text { Toma las fojas \& majalas \& } \\
\text { ayuntalas con la farina del } \\
\text { ordio o çeuada, que todo es } \\
\text { vno; \& fazlo enplasto \& } \\
\text { ponlo sobre las finchaduras } \\
\text { \& sanara. }\end{array}$ \\
\hline
\end{tabular}

En este fragmento se introduce una glosa semántica que no figura en $M A C$ : «farina del ordio o çeuada que todo es vno». Esta precisión permite conjeturar que la versión de SDM surge de otro texto en castellano y que, por alguna ra- 
zón, el copista decidió aclarar el término «ordio». Se da la circunstancia de que este mismo vocablo es utilizado en once pasajes en las demás versiones castellanas, sin que en ninguna de ellas aparezca glosa alguna que aclare su significado. Tal añadido podría justificarse de dos maneras: por una parte, puede tratarse de una copia realizada en un lugar geográfico alejado del noreste peninsular, probable zona de difusión primera del Macer Floridus, con influencia del término catalán «ordi» ${ }^{36}$. Otra hipótesis, que considero más probable, es que la copia pudo haberse realizado en un momento en que este vocablo dejó de ser común en castellano como sinónimo de «cebada». El primer texto que muestra el $\mathrm{CORDE}^{37}$ en el que aparece una glosa semejante a la de SDM, figura en el Libro de Palladio de Ferrer Sayol fechado entre 1380 y $1385^{38}$.

El ordio o çeuada trensmesor conujene a saber que en espaçio de tres meses es sembrado \& cogido.

El siguiente testimonio pertenece al texto que nos ocupa, datado en 1471; esto apunta como más verosímil la hipótesis de que se trata de una versión castellana del Macer Floridus más reciente que los otros textos castellanos ${ }^{39}$.

Más allá de sus aportaciones, la dificultad ya expuesta para comprender algunas divergencias textuales se debe a que nos hallamos ante pasajes fragmentarios y con importantes deturpaciones. Es necesario analizarlo con precaución para no considerar como generalidades elementos y errores propios de esta versión. Es más, las deturpaciones son otra característica del extracto que nos ocupa, junto a la variación léxica y a un estilo más formulario. Estos errores son consecuencia, bien de lagunas (primer ejemplo), bien de variaciones de la misma receta (ejemplos siguientes):

\footnotetext{
${ }^{36}$ Conviene señalar que el texto latino utiliza a menudo el término «hordeum», por lo que podría tratarse de una traducción literal y no necesariamente de un catalanismo. No es el caso en este pasaje concreto, pues el latín presenta «polentam». Por otra parte, existe otro texto divergente entre las versiones peninsulares, también en el capítulo del CORIANDRUM, donde el latín presenta «fabae... Farina», el catalán «farina de faves» y el castellano «farina de ordio». Además, no existe ningún testimonio de la voz «cebada» o de sus variantes gráficas en las versiones castellanas de este herbario.

${ }^{37}$ Esta base de datos documenta «ordio» desde el siglo XI en diversas localizaciones geográficas.

${ }^{38}$ Ferrer Sayol, Libro de Palladio, BNM 10211, ed. Pedro Sánchez-Prieto Borja, Alcalá de Henares, Universidad de Alcalá, 2004 (apud RAE, CORDE, 06-03-2010).

${ }^{39}$ El códice Zabálburu está fechado en el siglo XIV (cfr. María Teresa Llera Llorente, «El estudio de los fondos de la biblioteca Francisco de Zabálburu: los manuscritos», Revista general de información y documentación, 15, 2, 2005, págs. 103-128).
} 


\begin{tabular}{|c|c|c|c|}
\hline Macer latino & $Z$ & $M A C$ & $S D M$ \\
\hline $\begin{array}{l}\text { (vv. 1610-1613) } \\
\text { Illius in vino } \\
\text { decoctio saepius } \\
\text { hausta / Vesicae } \\
\text { duros sedat sic } \\
\text { sumpta dolores, / Et } \\
\text { scotosim sic illa } \\
\text { iuvat stomachique } \\
\text { dolorem, / } \\
\text { Nefreticos eadem } \\
\text { multum iuvat, } \\
\text { ictericosque. }\end{array}$ & $\begin{array}{l}\text { [60ra] E ha otra } \\
\text { virtut, que si es } \\
\text { cocha con vino e es } \\
\text { bevida, aprovecha } \\
\text { mucho al dolor de la } \\
\text { coxa e al dolor de la } \\
\text { bexiga e al dolor del } \\
\text { vientre e <a } \\
\text { aquéllos que han } \\
\text { mal en las renes e a } \\
\text { los que han la tos. }\end{array}$ & $\begin{array}{l}\text { [16v] Et sy es cocha } \\
\text { con vjno \& es } \\
\text { beujda aprouecha } \\
\text { mucho al dolor de la } \\
\text { pierrna Et al dolor } \\
\text { de la bexiga \& al } \\
\text { dolor del vientre Et } \\
\text { aquellos que an } \\
\text { malas orynas Et } \\
\text { aquellos que an tos. }\end{array}$ & $\begin{array}{l}\text { [14ra] Yten, sy esta } \\
\text { yerua es cocha con } \\
\text { vjno \& beues della, } \\
\text { aprouecha al dolor } \\
\text { de la vexiga \& de } \\
\text { las renes. }\end{array}$ \\
\hline $\begin{array}{l}\text { (vv. 1610-1613) } \\
\text { Illius in vino } \\
\text { decoctio saepius } \\
\text { hausta / Vesicae } \\
\text { duros sedat sic } \\
\text { sumpta dolores, } \\
\text { Et scotosim sic illa } \\
\text { iuvat stomachique } \\
\text { dolorem, / } \\
\text { Nefreticos eadem } \\
\text { multum iuvat, } \\
\text { ictericosque. }\end{array}$ & $\begin{array}{l}\text { [60ra] E ha otra } \\
\text { virtut, que si es } \\
\text { cocha con vino e es } \\
\text { bevida, aprovecha } \\
\text { mucho al dolor de la } \\
\text { coxa e al dolor de la } \\
\text { bexiga e al dolor del } \\
\text { vientre e <a } \\
\text { aquéllos que han } \\
\text { mal en las renes e a } \\
\text { los que han la tos. }\end{array}$ & $\begin{array}{l}\text { [16v] Et sy es cocha } \\
\text { con vjno \& es } \\
\text { beujda aprouecha } \\
\text { mucho al dolor de la } \\
\text { pierrna Et al dolor } \\
\text { de la bexiga \& al } \\
\text { dolor del vientre Et } \\
\text { aquellos que an } \\
\text { malas orynas Et } \\
\text { aquellos que an tos. }\end{array}$ & $\begin{array}{l}{[14 \mathrm{ra}] \text { E si esta }} \\
\text { yerua es beujda, } \\
\text { purga la piedra de la } \\
\text { vexiga \& faz bien } \\
\text { mear. } \\
(\ldots) \text {... } \\
{[14 \text { ra }] \text { Yten, sy esta }} \\
\text { yerua es cocha con } \\
\text { vjno \& beues della, } \\
\text { aprouecha al dolor } \\
\text { de la vexiga \& de } \\
\text { las renes. }\end{array}$ \\
\hline
\end{tabular}

\begin{tabular}{|l|l|l|}
\hline Macer latino & $F$ & $S D M$ \\
\hline $\begin{array}{l}\text { (vv. 2102-2103) } \\
\text { Unguine si totum corpus } \\
\text { mulcebitur isto, / Largos per } \\
\text { poros sudor procedet } \\
\text { apertos. }\end{array}$ & $\begin{array}{l}\text { aquest oli : que, si hon } \\
{[\text { hom] no pot suar, tantost }} \\
\text { suarà e ab la suor perdrà la } \\
\text { dolor. }\end{array}$ & $\begin{array}{l}\text { [14rb] E eso mesmo el que } \\
\text { non puede sudar vntese con } \\
{[14 \mathrm{va}] \text { este oleo \& sudara. }} \\
{[14 \mathrm{va}] \text { Otrosy, sy vntas con }} \\
\text { este oleo todo el cuerpo no } \\
\text { ayas mjedo de njngund frio. }\end{array}$ \\
\hline
\end{tabular}

Algunos de estos errores léxicos son fácilmente subsanables con ayuda de otras versiones castellanas, como sucede en los siguientes pasajes, en los que se observa un cambio, en principio inexplicable, de «uva pasa» por «vinagre», y un claro error de interpretación del término «çerusa» (tex. lat. 'cerussae') interpretado en $S D M$ por «escoria»:

\begin{tabular}{|c|c|c|c|}
\hline Macer latino & $Z$ & $F$ & $S D M$ \\
\hline $\begin{array}{l}\text { (vv. 962-963) } \\
\text { Uva cum passa } \\
\text { Coriandrum melque } \\
\text { iugatum / Sedabunt } \\
\text { varios superaddita } \\
\text { trita tumores. }\end{array}$ & $\begin{array}{l}\text { [52rb] E ha otra } \\
\text { virtud, que si es } \\
\text { mezclada con uva } \\
\text { pasa o con miel e es } \\
\text { bien majada, tuelle } \\
\text { el dolor del vientre. }\end{array}$ & $\begin{array}{l}\text { [26a] Item, si és } \\
\text { picada ab panses e } \\
\text { ab mel, toll totes } \\
\text { dolors }\end{array}$ & $\begin{array}{l}\text { [13vb] Otrosy, sy lo } \\
\text { mesclas con vinagre } \\
\& \text { con mjel \& sea } \\
\text { bien pisada \& } \\
\text { beujda quita todo } \\
\text { dolor de todos los } \\
\text { mjenbros. }\end{array}$ \\
\hline
\end{tabular}




\begin{tabular}{|c|c|c|c|}
\hline Macer latino & $Z$ & $F$ & $S D M$ \\
\hline $\begin{array}{l}\text { (vv. 967-973) } \\
\text { Argenti spumam } \\
\text { cerussae contere } \\
\text { mixtam / His tritis } \\
\text { succum Coriandri } \\
\text { iunge et acetum, / } \\
\text { Quattuor his roseum } \\
\text { miscendo iugabis } \\
\text { olivum, / Ista } \\
\text { terendo simul } \\
\text { pretiosum conficis } \\
\text { unguen, / Quo } \\
\text { sacros ignes pellas } \\
\text { calidosque tumores; } \\
\text { / Si tibi difficilis } \\
\text { confectio tanta } \\
\text { videtur, / Succus } \\
\text { cum solo prodest } \\
\text { commixtus aceto. }\end{array}$ & $\begin{array}{l}\text { [52va] E ha otra } \\
\text { virtud, que si tomas } \\
\text { el espuma del } \\
\text { argente e la çerusa e } \\
\text { el çumo del culantro } \\
\text { e el vinagre e lo } \\
\text { ayuntas todo esto en } \\
\text { uno, farás un } \\
\text { preçioso engüento, } \\
\text { que es muyn } \\
\text { provechoso } \\
\text { ungüento para matar } \\
\text { el fuego salvaje e } \\
\text { para los calores de } \\
\text { las finchaduras, si } \\
\text { son untadas. }\end{array}$ & & $\begin{array}{l}\text { [13vb] Otrosy, toma } \\
\text { la espuma del argen } \\
\& \text { la escoria \& el } \\
\text { çumo del culantro \& } \\
\text { el vjnagre \& } \\
\text { ayuntalo todo \& faz } \\
\text { vnguento muy } \\
\text { prouechoso para el } \\
\text { fuego saluage \& } \\
\text { para las finchaduras. }\end{array}$ \\
\hline
\end{tabular}

En otros pasajes no es posible saber si el error proviene de esta versión en particular o si se debe extender a la traducción castellana:

\begin{tabular}{|l|l|l|}
\hline Macer latino & $\boldsymbol{F}$ & SDM \\
\hline (vv. 2185-2189) & [60d] E la decocció d'ell & {$[14$ ra] E cuezelo con vjno \& } \\
Et renes illius apozima & purga los ronyons e la & beuelo \& purgara las renes \\
purgat, / Vesicam iuvat, & vexiga e la fa ben pixar, e & \& la vexiga \& faz bien mear \\
urinas et menstrua pellit, / & delliura la sobirana sanch de & \& estaña la sangre de la \\
(...) / Puncturas aufert et & la fembra e toyl los morsos & muger \& quita el dolor de \\
morsus interiorum. & dels budells. & las piernas. \\
\hline
\end{tabular}

Se produce aquí una deturpación del texto de la Real Biblioteca frente a la versión catalana, más cercana al latín, que traduce 'morsus interiorum' como «morsos dels budells». En su lugar, la copia castellana presenta «dolor de piernas», que no figura en ninguna de las versiones latinas de la SPICA colacionadas por Ludwig Choulant. Parece claro que este error no proviene del catalán, pues no hay ninguna similitud fonética ni semántica entre «budell» (intestino) y «pierna», de manera que no parece existir ninguna dependencia de $S D M$ con respecto a los textos catalanes. Pero tampoco es posible saber si se trata de un error específico de esta versión (o de una familia concreta de la transmisión textual); o bien si es común a todos los textos castellanos, remontando tal deturpación a la traducción castellana del pasaje. La respuesta a tal interrogante está supeditada a la aparición de nuevas redacciones y a la publicación de la traducción aragonesa para arrojar nueva luz, quizás definitiva, sobre tales interrogantes. 
En cualquier caso, la interpolación del Macer Floridus en el manuscrito RB II-3063 constituye una aportación breve pero esencial para la constitución de su edición castellana. Contiene pasajes deturpados, más formularios, debido a una posible modernización del texto castellano. Pero recoge también la descripción de dos plantas del herbario latino de las que no se conocía traducción castella$\mathrm{na}^{40}$, aclara algunos pasajes oscuros y contribuye, en definitiva, a mejorar nuestro conocimiento de la transmisión romance del Macer Floridus en la Península Ibérica.

\section{BIBLIOGRAFÍA}

Anónimo, Códice Zabálburu de Medicina Medieval, trscr. de C. Sánchez Téllez, Alcalá de Henares, Universidad de Alcalá, 1997.

Bos, Gerrit y Mensching, Guido, «Macer Floridus: A Middle Hebrew Fragment with Romance Elements», The Jewish Quarterly Review, New Series, 91, 1/2 (Jul. - Oct.), 2000, págs. 17-51.

Brunel, Clovis, Recettes médicales, alchimiques et astrologiques $d u X V$ siècle en langue vulgaire des Pyrenées, Toulouse, Édouard Privat, 1956.

Capuano, Thomas M., «Medieval iberian vernacular versions of the herbal called Macer Floridus», Manuscripta, a journal for Manuscript Research, November, 1991, págs. 182-202.

Corradini Bozzi, María Sofía, Ricettari medico-farmaceutici medievali nella Francia meridionale, vol. I, Firenze, Olschki Ed., 1997.

Enríquez, Juan, Secretos de la medicina, Madrid, Biblioteca de Palacio 3063, ed. E. Jiménez Ríos, Madison, Hispanic Seminary of Medieval Studies, University of Wisconsin.

Faraudo de Saint Germain, Lluís, «Una versió catalana del libre de les herbes de Macer», Estudis Romànics, 5, 1955-1956, págs. 1-54.

Ferraces Rodríguez, Arsenio, Estudios sobre textos latinos de fitoterapia entre la Antigüedad tardía y la Alta Edad Media, A Coruña, Universidade da Coruña, 1999.

Gottfried Mayer, Johannes y Goehl, Konrad, Kräuterbuch der Klostermedizin: Der «Macer Floridus», Medizin des Mittelalters, Holzminden, Reprint-Verlag-Leipzig, 2003.

Kinkade, Richard P., «Un nuevo manuscrito de la Semeiança del mundo», Hispanic Review 39, 1971, págs. 261-262.

Lenkiewicz, Marie, Contribución al estudio del léxico médico del español medieval: «Secretos de medicina» del licenciado don Juan Enríquez y «Pronóstica del pseudo-Galeno», tesis de «Master of Arts», Department of Hispanic Studies, Montreal, Mc Gill University, 1987.

Llera Llorente, $\mathrm{M}^{\mathrm{a}}$. T., «El estudio de los fondos de la biblioteca Francisco de Zabálburu: los manuscritos», Revista general de información y documentación, 15, 2, 2005, págs. 103-128.

Macer Floridus, De viribus herbarum, ed. y notas de L. Choulant, Leipzig, Leopold Voss, 1832.

Macer herbolario, Sevilla, Bibl. Colombina 7-6-27-1, ed. Porter Conerly, Enrica J. Ardemagni y Ruth C. Richards, Madison, Hispanic Seminary of Medieval Studies, University of Wisconsin, 1986

${ }^{40}$ Esta aportación se suma a las realizadas por el manuscrito de la biblioteca Zabálburu de Madrid, que presenta un orden de plantas semejante al texto latino, hasta ahora específico de las versiones catalanas. Además, recoge la versión castellana del «SERPILLUM», única en las versiones en romance del De viribus herbarum. Gracias a la contribución de estos dos textos, disponemos de un corpus de 64 plantas de las 77 descritas en el Macer Floridus. 
Macer, Llibre de les herbes i les seues virtuts, I, Transcripcio, ed. e intr. d'Alicia Palazón, Valencia, L'Oronella, serie L'Alfardó, $\mathrm{n}^{\mathbf{o}}$ 2, Conselleria d'agricultura, peixca i alimentació de la Generalitat valenciana, 2001.

Macer: Llibre de les herbes i les seues virtuts, II, actualisacio, ed. e intr. F. Tarazona, Valencia, L'Oronella, serie L'Alfardó, $\mathrm{n}^{\mathrm{o}}$ 3, Conselleria d'agricultura, peixca i alimentación de la Generalitat valenciana, 2002.

Mensching, Guido, «El Macer Floridus en la Península Ibérica: efectos y efectos secundarios de un herbario medieval», en $\mathrm{M}^{\mathrm{a}}$. T. Navarro, J. J. Nitti y $\mathrm{M}^{\mathrm{a}}$. N. Sánchez, coords., Textos medievales y renacentistas de la Romania, New York, Madison, Hispanic Seminary of Medieval Studies, University of Wisconsin, 2002, págs. 93-109.

Pensado Figueiras, Jesús, El códice Zabálburu de medicina medieval: Edición crítica y estudio de fuentes, tesis doctoral, A Coruña, Universidade da Coruña.

Ramello, Laura, «Una raccolta di ricette in antica lingua catalana (códice palatino 1052 della Biblioteca Nazionale di Firenze)», Quaderni di Filologia Romanza, II, 1994, págs. 99-136.

Corpus Diacrónico del Español (CORDE) [RAE, http://www.rae.es].

Rocha Pereira, María Helena da, Obras médicas de Pedro Hispano, Coimbra, Acta Universitatis Conimbrigensis, 1972.

Sayol, Ferrer, Libro de Palladio, BNM 10211, ed. P. Sánchez-Prieto Borja, Alcalá de Henares, Universidad de Alcalá, 2004.

Soriano, Jerónimo, Libro de experimentos medicos, faciles y verdaderos, recopilados de grauissimos autores (Zaragoza, 1598), ed. de $\mathrm{M}^{\mathrm{a}}$ Teresa Herrera y $\mathrm{M}^{\mathrm{a}}$ Estela González de Fauve, Madison, Hispanic Seminary of Medieval Studies, University of Wisconsin, 1997.

Fecha de recepción: 22 de julio de 2010

Fecha de aceptación: 12 de septiembre de 2011 